\title{
A Guide to Europhysics Conferences
}

\section{Prepared by the Advisory Committee on Conferences (Chairman: G. H. Stafford), approved by the Executive Committee and adopted by Council}

\section{New address for EPS}

The Main Secretariat of the European Physical Society has moved to a new address. In future, all correspondence on EPS matters, as well as for Europhysics News, should be sent to :

European Physical Society, P.O. Box 39, CH - 1213 PETIT-LANCY 2, Switzerland Telephone : Geneva 931130

\section{Contents}

New address for EPS . . . 1 Europhysics Conference Guide . . . . . . 1 Guide to Entries . . . . . 5 Conferences 1972-1974 . . 5 'Summer' Schools 1972 . . 11

\section{INTRODUCTION}

Co-ordinating and sponsoring conferences is one of the ways in which the European Physical Society can achieve its objective of promoting the advancement of physics. This conference scheme is put forward as an advisory document for the guidance of conference organizers; it is not intended to be rigid or mandatory, and EPS will always consider proposals* that conform to the spirit of the scheme. Although there is obviously no intention to interfere with established conference series, or with events organized by adhering societies, it is desirable to avoid duplication and overlap. It is therefore to be hoped that EPS will, in time, come to be regarded as the natural co-ordinator of meetings of a predominantly European character.

The European character should be reflected in the composition of the advisory committee which decides upon the programme, and in the nationalities of the lecturers. Although it is now common for conferences organized by national societies to be open to participants from other countries, this does not necessarily make them European in the sense of this scheme. EPS recognizes that, for a variety of reasons,

\section{* Applications}

In the first instance, all enquiries about EPS Sponsorship and for the 'Europhysics' label for Study Conferences should be sent to

Main Secretariat,

European Physical Society,

P.O. Box 39,

CH - 1213 PETIT-LANCY 2,

Switzerland.

The Main Secretariat will then forward a Questionnaire for completion and return. there will always be a place for national events. At the other end of the spectrum are the conferences organized on a worldwide basis and supported by organizations such as the International Union of Pure and Applied Physics.

The conferences with which EPS is concerned are those organized (i) by its own specialized Divisions, Sections and InterDivisional Groups and (ii) by external bodies which apply for EPS sponsorship. It is usual for proposals from external bodies to have been discussed by the appropriate Division before coming to the Advisory Committee on Conferences. There will, however, be cases where this is not possible because the topic is not clearly in the field of any one Division. If a proposed conference is judged to have satisfied the conditions laid down in the -Criteria for Sponsorship' (which relate to timeliness, standard of contributions, and international character ; see Appendix II), EPS sponsorship may be granted. Sponsorship ensures that there will be no clash with other European conferences in the same field ; it also confers a status on the conference that should assist in securing full attendance and adequate funding.

\section{TYPES OF CONFERENCE}

This scheme deals with four categories of conference. These are at present considered sufficient to cater for the needs of the European physics community. In the future it may, however, become necessary to add to these in order, to accommodate unusual requirements, the possibility of changes in EPS internal structure, and the development of physics itself.

The four categories of conference are Divisional, Topical, Study and 'Summer' School ; except for Divisional Conferences, proposals for each type may originate either from within EPS or externally. 
Each type of conference has the word 'Europhysics' attached to it, if it is organized by an EPS Division, Section or Inter-Divisional Group. This is a reversal of the original intention to reserve the use of 'Europhysics' for Study Conferences. Conferences organized by other bodies are termed 'sponsored by EPS' with the exception of Study Conferences. Since this type of meeting has special characteristics laid down by EPS, the label 'Europhysics' is always used. The term is used in a general sense elsewhere (Europhysics News, Europhysics Journals) and it is now accepted that there will be less misunderstanding if a more specific usage in the conference sphere is avoided.

The EPS General Conference is not included in this scheme. Among the aims of the EPS General Conference is the promotion of inter-disciplinary thought and an assessment of the contribution that physics is making to modern science and human affairs. It is therefore an event of a very special character for which detailed guidelines should not be laid down. The specialized EPS Divisions contribute most of the sessions of the General Conference and should therefore bear this in mind when planning their future conference programme.

\section{(a) Europhysics Divisional Conference}

This term means a general meeting of a Division (or Inter-Divisional Group), probably including a business session. The term 'Divisional Conference' should not be applied to other meetings organized by a Division; these will fall into one of the categories (b)-(d) described below.

The duration and frequency of Europhysics Divisional Conferences may vary from one Division to another. If a regular yearly or two-yearly pattern is established, the Division should be prepared to interrupt it to avoid clashing with major world-wide meetings in their field, for example the biennial or triennial meetings of the specialist IUPAP Commissions. Specialized Divisions should maintain close contact with the Advisory Committee on Applied Physics and Physics in Industry, to ensure that topics of common interest are adequately covered, both at Europhysics Divisional Conferences and at other meetings.

\section{(b) Topical Conference}

This is the conventional scientific conference on one specific topic or several closely related topics. Meetings of this type have been taking place for many years, sometimes under the auspices of a national physical society, sometimes organized by a research laboratory or a university. Apart from a half-day relaxation break in week-long conferences, the timetable is fully occupied by plenary and parallel sessions. Research results are reported in both invited and contributed papers, the former usually being reviews of recent progress and existing problems. A Topical Conference sometimes concludes with a session at which rapporteurs summarize the work presented at the parallel sessions.

It is expected that the majority of applications for sponsorship will be in the category of Topical Conference.

\section{(c) Europhysics Study Conference}

(previously known as 'Europhysics Conference')

Europhysics Study Conferences are working meetings similar in style to the well-known Gordon series in the USA. Their distinguishing feature is that the formal presentations are specifically designed to stimulate discussion. The conference timetable should include substantial allocations of time for such organized discussion, and also for developing privately or in small groups ideas thrown up during the formal sessions. There is a clear distinction in style between Europhysics Study Conferences (which are fairly loosely structured working meetings) and Topical Conferences (which are more rigidly timetabled meetings for the reporting of current work).

To make the study group concept workable, the subjects for Europhysics Study Conferences must be specific and well-defined and the attendance (by invitation only) should be restricted to about 70 active workers in the field under discussion. These intensive study meetings are of great potential value, and EPS intends to devote specia attention to promotion of the idea of Europhysics Study Conferences, which are described more fully in Appendix I.

\section{(d) 'Summer' School}

The important distinguishing feature of these events is that they are basically pedagogic. They can, however, contain a research element and EPS will concentrate initially on this type. They are intended primarily for young physicists (pre-doctoral or just post-doctoral status) though they would also be suitable for the mature physicist changing his speciality. An Advisory Committee on 'Summer' Schools and Student Exchanges has been established and it will eventually take over the responsibilities for 'Summer' Schools hitherto exercised by the Advisory Committee on Conferences.

\section{SITES FOR CONFERENCES}

In general, it seems best to avoid fixed venues. EPS is anxious to rotate its major events among the countries of all its adhering societies, since this can be beneficial to the development of physics in the host nations.

Most of the adhering societies have stated that they are able and willing to accommodate major EPS events either now or in the near future. Europhysics Study Conferences and 'Summer' Schools, however, may benefit from following or establishing a tradition for sites (such as Les Houches and Varenna) which possess the 'pleasant isolation' that these events need. Topical Con- ferences (probably the largest category) have no special requirements, though it may be necessary to adhere to a tradition if an established series is taken over by EPS.

Despite the apparent attractions, organizers are advised to avoid cities during events such as international fairs, since accommodation, meals and transportation are all scarcer and more expensive. Conference organizers can assist the Advisory Committee on Conferences by reporting on the suitability of venues.

\section{PUBLICITY AND PUBLICATIONS CONNECTED WITH CONFERENCES}

Annoucements inviting applications to attend should be made in Europhysics News, in the appropriate journals and in lists such as that published by the IAEA, preferably 12 months in advance.

There are, as yet, no plans to establish an EPS Conference Proceedings series. A paper in conference proceedings is not usually considered a substitute for formal publication in a learned journal, unless the proceedings appear as a special number of such a journal, in which case a high standard is ensured by the normal editorial and referee system. A scheme which has been used is to reproduce (with a limit of about four pages per paper) directly from the authors' typescripts. This has been done sucessfully by several recent conferences. The process can be quick and cheap. This is more important than typographical excellence, when it is remembered that proceedings normally have a limited useful life.

It is recommended that the conference fee should not include the cost of the proceedings, for which a separate charge should be made.

Europhysics Study Conferences are in a special position as regards publication. In order to encourage free discussion, the practice is not to publish any proceedings or other detailed report, unless the conference participants specifically decide to do so.

\section{FINANCING OF CONFERENCES ORGANIZED BY EPS DIVISIONS, SECTIONS AND INTER-DIVISIONAL GROUPS}

Because of the wide variation in size and complexity of the various types of conference in this scheme, it is not possible to have one standard fee for all events. Each individual conference should aim to be self-supporting and organizing committees should fix the conference fees at a level which will ensure this. To encourage people to join EPS and adhering societies, there should be two levels of fee; one for EPS members and members of adhering societies and a higher one for non-members. Special financial arrangements may be made for students, and for participants from countries with currency convertibility problems.

Organizers are encouraged to seek support from other sources. In particular, finan- 
cial contributions can often be obtained from industrial organizations whose interests are connected with the conference topic, particularly if they are given facilities to exhibit their products. Other support may be obtained from host universities, municipalities, governments, or specialist international agencies (for example, IAEA). If the organizers intend to approach other international bodies, they should give advance notification to the Main Secretariat of EPS, to ensure that there is no conflict of plans.

It is difficult to budget accurately in advance, since the conference fee has to be fixed before the total attendance, the expenses of invited speakers, and many other costs are known. In some cases, there will be unused income, which should be paid into a Europhysics Conference Fund. This Fund will be used as a last resort, to balance the accounts of a conference which has resulted in an unforeseen and unavoidable loss. No automatic grants will be paid from the Fund and its existence does not relieve conference organizers of the responsibility of trying to break even. Conference organizers are asked to provide the Advisory Committee on Conferences with a summary of their final financial position. This will enable the Committee to keep the situation under review and to give advice to other organizers.

\section{Appendix I - Europhysics Study Conferences}

\section{General}

Europhysics Study Conferences should follow broadly the philosophy and organization of the US Gordon Conferences, that is :

The subject of each conference should be well-defined and of topical interest.

The number of participants should preferably not exceed 70 , and 100 should be regarded as a limit. The number of participants from any single country should not exceed one-third of the total.

Attendance should be by invitation only (see Section 3). Europhysics Study Conferences should be held, as far as possible, in secluded places, away from the distractions of large towns, but with facilities for outdoor recreation. Holiday and sporting resorts out of season, and boarding schools and colleges during vacations are obvious possibilities.

These conferences should normally last at least three full days, preferably four to five days, though intensive one-day seminars might be acceptable.

Long (45-60 minute) introductory papers should be given by specially invited speakers or discussion leaders.

Ample time should be provided for informal personal exchanges and discussion in small groups. For example, there may be a morning session centred round two introductory talks, an after-dinner session with one introductory talk, while the afternoon is kept free for recreation and informal discussions.
There should be no published proceedings of Europhysics Study Conferences, unless the participants specifically decide to do so.

\section{Organization}

This should be in the hands of at least two people from different countries one of them preferably a resident in the country where the conference is held. The organizers will be jointly responsible for

- drawing up the detailed programme

- choosing and inviting the discussion leaders and the other participants

- finance and the local arrangements

They should submit a report to the EPS Advisory Committee on Conferences.

\section{Participants}

Since Europhysics Study Conferences are intended to be study conferences rather than 'schools', participants should be chosen mainly from among those who are actively working in the particular field. Many of the participants will be selected by the organizers from among those who have applied to attend. For this selection to be comprehensive, it would seem necessary to advertise the dates and topics of the various Europhysics Study Conferences well ahead. This could be done by listing them separately in Europhysics News, in the Physics Bulletin of the Institute of Physics, Bulletin de la Société Française de Physique, and other national or international physics periodicals, for example, Physics Today.

As stated above, a total attendance figure of 100 is to be regarded as the maximum with about 70 as a desirable aim.

\section{Finance}

Each Europhysics Study Conference should be self-supporting. Since it is expected that discussion leaders will not have to pay for their board and lodging and that in most cases their travelling expenses will also be borne by the conference, other participants will have to pay a more than nominal registration fee. A figure of between Sw. Fr. 400 and Sw. Fr. 500 comprising registration fee, board and lodging, may be regarded as a guide for a five day conference.

Since it is not possible to budget exactly, some conferences may show a slight profit, other a slight loss, and a special Europhysics Conference Fund will be established, administered by the Main Secretariat of EPS in Geneva but constituting a separate account. Any surplus from conferences and donations for the general purpose of Europhysics Conferences will be paid into that account, which in turn, will pay out subsidies if necessary and - more important - provide a financial guarantee. It is expected that organizers will try to get financial help from their own industries and governments.

\section{Initiation and approval of conferences}

Most Europhysics Study Conferences will be proposed by the various Divisions of
New Books from North-Holland

\section{Microscopic Theory of the Nucleus}

by Judah M. Eisenberg, University of Virginia, and Walter Greiner, University of Frankfurt am Main.

NUCLEAR THEORY, Volume 3.

1972. approx. 516 pages. Dfl. 100.00 (ca. \$ 31.25) ISBN 0720402174.

CONTENTS : Introduction. Part I: Two-and Three-Nucleon Systems. The nucleon-nucleon interaction. The three-nucleon problem. Part II: Nuclear Matter. Formal theory of many-particle systems. Infinite nuclear matter. Part III: Theories of the Structure of Light Nuclei. HartreeFock and particle-hole formalisms, and the random phase approximation. Application of the Hartree-Fock and the particle-hole formathe Hartree-Fock and the particle-hole forma-
lisms. Nuclear rotations. Part IV : Theories of the Structure of Heavier Nuclei. Pairing and quasiparticles. Collective motion in nuclei. Appendices : The projection of physical states. Collective coordinates in a consistent microscopic theory.

\section{Crystal Growth 1971}

Proceedings of the Third International Conference on Crystal Growth, Marseille, France, 5-9 July, 1971.

Edited by R.A. Laudise, Bell Telephone Laboratories, U.S.A., J.B. Mullin, Royal Radar Establishment, Malvern, U.K., and B. Mutaftschiev, Université de Provence, Marseille, France.

Special Issue of the Journal of Crystal Growth, Vols. 13/14.

1972. $x x+867$ pages. Dfl. 240.00 (ca. \$75.00) ISBN 0720402409.

CONTENTS : Invited papers. Nucleation, surface diffusion, simulation of nucleation and growth. Adsorption and heterogeneous nucleation from the vapour phase. Crystal morphology, growth forms, epitaxy. Crystal-melt interface, growth of ice. Characterization and assessment of crystal perfection. Vapour growth. Electrocrystallization. Solution growth. Industrial bulk crystallization. Hydrothermal growth. Flux growth. Melt-growth - basic studies and semiconductors. Melt growth mainly oxides. Eutectics, dendrites, inclusions. Segregation and defects. Solid state transformations. Author index. Subject index.

\section{The Practitioner's Shell Model}

by George F. Bertsch, Michigan State University.

1972. approx. 200 pages. Dfl. 36.00 (ca. \$ 11.25) Paperback. ISBN $072040214 \mathrm{X}$.

CONTENTS : Many-body theory and the shell model. Harmonic oscillator wavefunctions. Angular momentum. The nuclear force. Two-body correlations. Many-particle correlations: deformations and aligned coupling. Core polarization. Nuclear reactions. Appendices : LS-ji recoupling coefficients. Problem hints and solutions. References. Index.

\section{NORTH HOLLAND}

P.O. Box 3489 - Amsterdam - The Netherlands. 
EPS, although individual physicists may also suggest topics, especially in fields not properly covered by the Divisions. All Europhysics Study Conferences should be approved by the Advisory Committee on Conferences, but this is done by letter without having to wait for a committee meeting. A subcommittee assists the Chairman by examining the proposals, ensuring that there is no overlap in time or duplication in subject among the Europhysics Study Conferences themselves or with other meetings, and by checking that the conditions laid down in Section 1 are fulfilled. This subcommittee also keeps an eye on the finances and ensures that all adhering societies are fully informed about Europhysics Study Conference activities.

\section{Appendix II - Criteria to be satisfied by conferences organized or sponsored by the European Physical Society}

\section{Scientific value}

(a) There should be a clearly demonstrated need for the proposed conference, that is, new and important advances since the last conference of a similar type took place.

(b) The invited speakers and the papers accepted for discussion should be of high calibre.

Technische Hogeschool Eindhoven

Postbus 513, Eindhoven

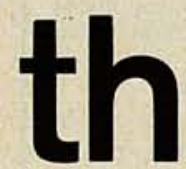

The Eindhoven University of Technology hereby invites applications for the Chair of

\section{Professor of Electromagnetic Theory}

at the

\section{Department of Electrical Engineering}

The assignment comprises the teaching of electromagnetic field theory, the fundamentals of which are given earlier in the curriculum, as well as a number of senior lectures on topics arising from research activities of the group "Theoretische Elektrotechniek".

The present and future scope of the research programme covers all aspects of the electromagnetic field theory, specifically applications of microwave techniques to aperture antennae and wave propagation in semiconductors.

The primary object of the group is to incorporate mathematical and physical aspects in the research activities of the department, in concert with the related circuit theory group.

Candidates must be prepared to co-operate with the associate professor and co-workers.

Applications, or references to possible candidates are to be directed by letter before July 15, 1972, to the Board of the

Department of Electrical Engineering,

University of Technology, P.O. Box 513 ,

Eindhoven, Netherlands.

(c) Acceptance of communications should be based on some sort of refereeing system which ensures a level comparable with that of papers in the regular journals.

\section{International character}

(a) There should be an International Advisory Committee to advise on the scientific programme and on the names of the lecturers. At least $50 \%$ of this Committee should be from countries whose national societies adhere to EPS (Ordinary Members, Article 4 (b)). With the agreement of the International Advisory Committee, the detailed organization and the refereeing of communications may be in the hands of a local organizing committee.

(b) Participation should be genuinely international, both as regards participants and invited speakers. The aim should be that at least one half of the invited speakers, rapporteurs and discussion leaders should come from outside the host country.

(c) Attendance must be independent of nationality or citizenship. The International Advisory Committee should, in addition, ensure an appropriate geographical distribution of participants.

(d) EPS will only sponsor conferences on the understanding that for the venue chosen there will be no restriction on the attendance of members from anywhere (By-laws, Rule 32).

(e) EPS sponsorship relates to meetings with a predominantly European character.

\section{Organization}

Sponsorship is granted by the Executive Committee of the European Physical Society on the recommendation of the Advisory Committee on Conferences. Application to the Advisory Committee on Conferences for sponsorship should be supported by the information listed on the accompanying questionnaire.

Requests* for sponsorship accompanied with the filled-in questionnaire should whenever possible, be received by the Main Secretariat of EPS in Geneva 12 months prior to the conference concerned.

\footnotetext{
* Applications

In the first instance, all enquiries about EPS Sponsorship and for the 'Europhysics' label for Study Conferences should be sent to

Main Secretariat,

European Physical Society,

P.O. Box 39 ,

CH - 1213 PETIT-LANCY 2,

Switzerland.

The Main Secretariat will then forward a Questionnaire for completion
} and return. 